\title{
LA FINALIDAD DE LAS PENAS EN REFERENCIA AL NUEVO CÓDIGO PENAL DECRETO 130-2017
}

\section{Jacobo Calix Hernández ${ }^{1}$}

DOI: https://doi.org/10.5377//rd.v41i1.10495

\section{RESUMEN:}

Recientemente entro en vigor un nuevo Código Penal contenido en el Decreto 130-2017, siendo ya el quinto Código Penal que rige los delitos y las penas en nuestro país; hecho histórico que consideramos no debe pasar inadvertido en la actividad académica, más aún cuando sabemos previo a su entrada en vigencia existió una gran polémica sobre la conveniencia o no de este nuevo orden normativo; discusión que si bien en gran medida ha tenido matices políticos, es precisamente desde la academia que se debe hacer un análisis con enfoque estrictamente jurídico, lo cual se pretende hacer en el presente artículo en lo concerniente a la finalidad de las penas y la regulación que de las mismas se hace en el nuevo texto punitivo; así como como su vinculación con lo principios de necesidad y proporcionalidad.

\section{PALABRAS CLAVE:}

Código Penal, Derecho Penal, penas, principio de necesidad de la pena, principio de proporcionalidad

Fecha de recepción:31 de agosto de 2020 Fecha de aprobación: 09 de noviembre de 2020 


\title{
THE PURPOSE OF THE PENALTIES IN REFERENCE TO THE NEW PENAL CODE DECREE 130-2017
}

\author{
Jacobo Calix Hernández ${ }^{2}$ \\ DOI: $\underline{\text { https://doi.org/10.5377//rd.v41i1.10495 }}$
}

\begin{abstract}
ABSTRAC
Recently a new penal code entered into force contained in decree 130-2017, already being the fifth Penal Code that governs crimes and penalties in our country; a historical moment that we consider should not go unnoticed in academic activity, even more so when, as we know, prior to its entry into force, there was great controversy about the convenience or not of this new normative body, a discussion that, although to a great extent, was with clear political nuances It is precisely from the academy that an analysis with a strictly legal approach must be carried out, which is intended to be done in the present work.
\end{abstract}

\section{KEYWORDS:}

Criminal Code, Criminal Law, Penalties, Principle of necessity of the penalty, Principle of proportionality.

Date received: August 31, 2020

Approval date: November 09, 2020

2 Teacher since 2001, de la Facultad de Ciencias Jurídicas UNAH. Email: jacobo.calix@unah.edu.hn 


\section{INTRODUCCIÓN}

La pena privativa de libertad siempre es la reacción punitiva más radical de las comprendidas en un Código Penal, la limitación del derecho a la libertad exige que la imposición de la pena además de las reglas de legalidad requeridas para el desarrollo del proceso penal en que se imponga tenga también determinada cuál es la finalidad constitucional y social que la pena debe de cumplir para tener a la vez legitimidad democrática.

En la actualidad, la pena privativa de libertad resulta imprescindible, dadas las condiciones sociales no es posible contar con un Derecho penal sin sanción punitiva; pero si es necesario que la sanción se justifique, es decir, axiológicamente debe tener una razón social que la explique jurídicamente, ya que como todos los temas de la parte general del Derecho penal, se encuentra vinculado con los aspectos propios de la teoría de la ley, la del delito y la de la pena misma, ello la vincula a principios de orden constitucional que determinan las garantías fundamentales relacionadas con la dignidad humana y su seguridad jurídica. Esta amplitud obliga al poder punitivo a mantener un equilibrio entre represión estatal, libertad, dignidad humana y proporcionalidad.

La legitimación del Derecho penal pasa por el contenido y finalidad de la sanción penal; llevando siempre un debate sobre la compatibilidad entre retribución y prevención, que en definitiva dependen del tipo de sanciones que se regulen o se haya decidido regular como política criminal; el Derecho penal al ser el ámbito en el cual más claramente se refleja el conflicto entre poder punitivo y derechos fundamentales debe necesariamente contener normas capaces de tutelar los derechos del ciudadano frente al arbitrio punitivo en tres momentos distintos de la restricción de derechos: cuando se define cuáles son las conductas antisociales merecedoras de ser delitos (criminalización primaria); cuando una persona es sometida a la investigación y condena por la comisión del delito ( criminalización secundaria); y cuando se aplica el castigo por la infracción cometida (ejecución de la pena).

El Estado de Derecho es aquel en el que el poder público se encuentra sometido a normas jurídicas que buscan racionalizarlo no solo en la forma sino también en su contenido, reflejándose directamente los derechos humanos cuyo respeto es la condición esencial de legitimidad del Estado, de sus actuaciones y existencia; resultando por ello, indispensable formular un Derecho penal en el que se respete la estricta legalidad, la necesidad y proporcionalidad de las penas, garantizando así seguridad jurídica. Lo cual resulta consecuente con un Derecho penal garantista, que es aquel limitado por el respeto irrestricto de los derechos humanos, definido como un Derecho penal de mínima intervención.

Para comprender el tema de las penas privativas de libertad es necesario también entender la incidencia que ha tenido siempre la exigencia social, así como las funciones ocultas que posee la pena, que en gran medida son las que restringen que la pena cumpla la función de rehabilitación que se le debe asignar como función social. 


\section{METODOLOGÍA}

Se utiliza tipología descriptiva, analítica y explicativa en general del tema que se aborda en el análisis dogmático para explicar los razonamientos de la normativa jurídica y las figuras penales que se vinculan en dicho análisis para buscar mayor claridad en lo argumentado, teniendo también en cuenta la importancia de la evolución histórica de las teorías que han pretendido justificar la legitimidad de las penas; tratando de circunscribir el tema a la legitimidad de la sanción penal y como aparece esa perspectiva desde la política criminal que se implementa en el nuevo Código Penal, haciendo referencia comparativa con el Código Penal derogado.

\section{EL CONTEXTO DEL NUEVO CÓDIGO PENAL}

Probablemente, por las condiciones político-sociales que ha venido viviendo el país en la última década el nuevo Código Penal (en adelante NCP), es el que mayor polémica haya generado; provocando una discusión que no se puede desconocer en gran medida ha sido de índole política, motivada por los altos índices de corrupción pública que se perciben en la actualidad y desde hace muchos años atrás, pues es frecuente darnos cuenta a través de los medios de comunicación y redes sociales de diferentes actos de corrupción en diversas modalidades y amplitudes, que siguen evidenciando la debilidad de los controles institucionales, aunado también a la pérdida de credibilidad de la clase política que legisla; sin embargo, no se puede desconocer que la añeja teoría de la representación popular sigue siendo el criterio valido de la legitimación del poder legislativo ${ }^{3}$, ciertamente, un problema de la democracia electoral.

De igual forma, en determinadas ocasiones la desconfianza a las legislaciones ha surgido de la desilusión, la confianza ingenua y desmedida en las capacidades del legislador para obtener soluciones a los problemas sociales mediante la formulación de normas generales y abstractas, que llevo a una suerte de inflación legislativa, que muchas veces logro resultados opuestos a los que intentaba conseguir, lo cual ha provocado una permanente tensión entre la autoridad del legislador y la autoridad de la ciencia jurídica; entre la voluntad política y el conocimiento científico, entre legislación y dogmática ${ }^{4}$.

3 Para los poderes ejecutivo y legislativo, la teoría de la representación sigue siendo un criterio valido de legitimación; contrario al poder judicial que carece de ese elemento similar de la representación para justificarse, en un sistema democrático su legitimidad debe contemplarse desde la perspectiva del control del poder. Vid. BALAGUER CALLEJON, María Luisa, Interpretación de la Constitución y Ordenamiento Jurídico, Tecnos, Madrid, 1997, p. 50.

4 Las decisiones del legislador tienen autoridad cuando ellas excluyen la formación de un balance de razones que indique qué se debe hacer. Para que sea posible desempeñar esa función, las decisiones deben expresar de manera precisa qué comportamientos son obligatorios, prohibidos y permitidos. En la medida en que esas normas sean vagas (o contengan conceptos morales abiertos al debate sobre su aplicación, o la formulación sea ambigua, etc.), los destinatarios de esas normas no tendrán más opción que reabrir el balance de razones y con ello, la legislación dejará de prestar el servicio que legitima su autoridad. El desafío que lanza la dogmática al papel del legislador comienza, a menudo, con la reivindicación del papel del intérprete como un complemento indispensable a la tarea del autor. Más allá de la mayor o menor pericia del legislador, la dogmática insiste en la inevitabilidad de la interpretación de las leyes. Pero, al margen de la ingenuidad del legislador o del descuido y arbitrariedad de muchos de sus proyectos legislativos, el valor de la ley como instrumento racional de control social también se ve amenazado por la permanente revisión y reformulación de las leyes que emprende la dogmática. Vid. MANRIQUE, María Laura, NAVARRO E, Pablo, y PERALTA, José, «La ley penal y la autoridad de la dogmática», Revus [Online], 31 | 2017. 
Precisamente, la función de la dogmática como precisara ROXIN es la de ser la disciplina que se ocupa de la interpretación, sistematización, elaboración y desarrollo de las disposiciones legales y opiniones de la doctrina científica en el campo del Derecho penal ${ }^{5}$.

Surgiendo el NCP en el contexto social referido, fácilmente fue percibido como un instrumento que no sería efectivo para combatir la corrupción, ante el descontento generalizado de la ciudadanía, resulta bien visto oponerse al NCP, en algunos casos sin mayores argumentos jurídicos $\mathrm{y}$ paradójicamente incurriéndose en el mismo "populismo", que se cuestiona a los que se encuentran actualmente en posición de poder político, que generalmente en todas partes son los que promueven penas draconianas y discursos políticos que causan el crecimiento desmedido del Derecho penal actual (el llamado discurso de la sociedad de riesgo) ${ }^{7}$, 5 CLAUS, Roxin, Derecho Penal Parte General, Civitas, Madrid, 1997, P. 192.

6 El llamado populismo punitivo apela al sentido común, teniendo su discurso una gran simpleza, lo que facilita una gran aceptación de la comunidad. Se parte que el individuo promedio sabe que la causa de la criminalidad es la lenidad del sistema penal. Se utilizan una serie de eslóganes de carácter pegajoso, a partir de "frases breves y llamativas", de carácter intuitivo, de modo que sean aceptadas sin mayor análisis, explotándose los prejuicios sociales. Así se dice que el "sistema penal garantiza los derechos de los delincuentes, pero no los de las víctimas” que "debe aplicarse mano dura contra la delincuencia", que "debe existir una política de medidas conocidas como de 'mano dura' (patrullaje militar de las ciudades, aumento de las penas por decreto, no se reconoce que las causas sociales como la pobreza y el desempleo generen aumento del delito, sino el exceso de garantías judiciales). Véase. LLOBET, JAVIER, Populismo Penal, en Revista Digital de la Maestría de Ciencias Penales No 8 Año 8 www.revistacienciaspenales.ucr.ac.cr

7 Cfr. SOTOMAYOR ACOSTA, Juan y TAMAYO ARBOLEDA, Fernando, La Nueva Cuestión Penal y Los Retos de Una Ciencia Penal Garantista, en Revista Nuevo Foro Penal, Vol. 10 No. 82 enero -junio 2014. Universidad EAFIT, Medellín Colombia, p. 180. que explica la sociedad moderna como una sociedad de riesgo global, promoviendo un discurso pidiendo mayor y más fuerte intervención punitiva, mutando el concepto teórico descriptivo de carácter sociológico a uno político- justificativo llevando un adelantamiento de la barrera de protección del Derecho penal, así como el desplazamiento de la protección de bienes jurídicos individuales a la protección de bienes jurídicos colectivos, la modificación de la punición de la lesión al bien jurídico a la mera creación del riesgo e incluso a veces la punición de riesgo disfrazado de supuesto peligro al legislarse tipos penales meramente abstractos.

Ciertamente, el NCP aparece con luces y algunas sombras, debe tenerse en cuenta como manifestaba el recordado profesor Rene Suazo Lagos" que: "Ninguno de los códigos penales que han regido en nuestro país ha estado precedido de una investigación científica de las condiciones nacionales que tenían que tomarse de base para la elaboración y aprobación del correspondiente proyecto. En nuestro país se ha utilizado tradicionalmente dos medios para la emisión de un Código Penal: uno copiando códigos de otro país; y dos, contratando expertos extranjeros para que elaboren los proyectos". Valoración que también es aplicable al NCP.

\section{DE LA EXIGENCIA DE PENAS ALTAS Y LA PERSECUCIÓN PENAL DEL DELITO}

\footnotetext{
8 Para una explicación amplia del desarrollo del Derecho penal hondureño. Vid. SUAZO LAGOS, Rene, La Evolución del Derecho Penal en Honduras, en CALIX HERNANDEZ, Jacobo, Temas de Derecho Penal, Libro Homenaje a José María Palacios, Corte Suprema de Justicia, Litografía López, 2014, p. 75.
}

Revista de Derecho. Vol. 41, No. 1, Año 2020 -121 
En nuestro país la exigencia de mayores penas siempre ha sido una constante que se pide desde la ciudadanía, en algunos momentos debido a los altos índices de criminalidad de todo tipo de delitos, que no se puede desconocer son fomentados muchas veces con el manejo mediático que se hace de la nota criminal, la vinculación entre los medios y la criminalidad se caracteriza a lo largo de los años por el manejo y la manipulación que los medios hacen de la violencia delictiva, que pasa de ser un tema de fuerte impacto social a producto de alto consumo, mediado por un discurso construido desde la lógica ideológica comercial que mueve la comunicación de masas $^{9}$; ( muchas veces incluso se ofrecen a la opinión pública casos de culpables que son inocentes; así como casos de inocentes que son culpables).

Debe tenerse en cuenta, como bien lo ha señalado la doctrina, que existen funciones ocultas de la pena privativa de libertad que no se puede desconocer fomentan el clamor popular de mayores penas; entre ellas, las de orden sico-social, especialmente en el ámbito de la opinión pública, situación que la hace muy vulnerable a la manipulación de los medios de comunicación colectiva, representándose en sus manifestaciones de: a) carácter vindicativo, que hacen que el sentimiento de venganza persista intacto en el ofendido y en la sociedad, las deplorables condiciones y excesivas restricciones de derechos en los centros penales, fortalecen ese sentimiento vindicativo; $\mathrm{y}, \mathrm{b}) \mathrm{de}$ cobertura ideológica, que se manifiesta en

9 Vid. PARRA GONZALEZ, Ana Victoria, Medios Opinión Publica y Corrupción, en CAPPAROS, Eduardo y PÉREZ CEPEDA. Ana, Estudios Sobre Corrupción, Ratio Legis, Salamanca, 2010, p. 14. dos aspectos (la responsabilidad social y el delito), básicamente desconociéndose la corresponsabilidad social respecto al surgimiento del delito ${ }^{10}$, el cual se le atribuye exclusivamente al privado de libertad que ha sido condenado ${ }^{11}$.

Lo anterior provoca, que frecuentemente se considere que el garantismo judicial es sinónimo de impunidad, cuando en realidad todo depende del buen trabajo de investigación y el rol del Ministerio Público en la adecuada investigación de los hechos delictivos, si hay suficientes elementos de prueba para imputar los hechos ilícitos, indistintamente de los derechos y garantías que se le deben respetar al acusado se podrá conseguir sentencias condenatorias, en ese sentido el "endurecimiento" de las penas científicamente nunca ha constituido una solución al problema delictivo, común, o de cuello blanco, la criminología ha demostrado por medio de la "teoría de la indiferencia de las sanciones penales", que cualquiera que sea la pena prevista en los códigos penales, ninguna en particular tiene incidencia en la disminución del delito; no obstante, cuando surge la preocupación ciudadana se

10 A partir de la década del 60 el fin de la pena se definió de una manera uniforme a través del concepto de resocialización, se procuró dar cabida a las consideraciones que ponen en manifiesto la corresponsabilidad de la sociedad en el delito, abandonando el causalismo antropológico y biológico de la época anterior, cuyo déficit de verificación empírica lo hacía científicamente insostenible. Vid. BACIGALUPO, Enrique, Manual de Derecho Penal, Temis, Bogotá, 1996, p.15.

11 Al trasladarse al infractor toda la responsabilidad por el delito, resulta inevitable la aplicación de una visión estrictamente retributiva de la pena y la exclusión de cualquier afán resocializador. Los factores sociales y políticos de la criminalidad se ignoran, invisibilizándose a sus responsables. Vid. CRUZ CASTRO, Fernando, La Pena Privativa de Libertad: Poder Represión y Constitución, Editorial Jurídica Continental, Costa Rica, 2004. P. 14. 
acostumbra responder desde la perspectiva política electoral con las propuestas de "mano dura", así en el país hemos visto como desde el modelo de la "cero tolerancia" iniciado en la gestión del ex presidente Maduro se enfatizó primordialmente en la persecución mediática de ciertos estereotipos de delincuente que causaban alarma social en ese momento, como una forma de vender a la ciudadanía -"Ley y Orden"12-, para persuadirla psicológicamente del temor al delito, incorporando incluso reformas en el Código Penal (vigente hasta el 25 de junio del 2020) en ciertos delitos en los cuales se sanciono hasta con la privación de libertad a perpetuidad, pero hasta la fecha no vemos un enfoque claro, sistemático y científico en la institucionalización del tema de la seguridad ciudadana y en la definición de una política criminal coherente para atender las verdaderas causas sociales como el elevado índice de pobreza y marginación social que inciden directamente en la criminalidad ${ }^{13}$.

12 Una de las armas para combatir que los partidos políticos y ciertos medios de comunicación [grupos sociales]hagan uso electoralista perverso del Derecho penal es que la población sea consciente de que ciertos mensajes sobre la ley y orden o sobre (in) seguridad ciudadana están construidos sobre creencias que, por ser generalizadas, no dejan de ser falsas. Penas más duras no garantizan una mayor seguridad. Ordenamientos penales de gran dureza como el estadounidense no son capaces de combatir unos índices enormes de delincuencia, mientras ordenamientos mucho más suaves o tolerantes con un índice de encarcelamiento muy bajo como los escandinavos o el alemán son capaces de mantener unos índices razonables de delincuencia, especialmente de la delincuencia violenta que más preocupa a los ciudadanos. Vid. FEIJOO, Bernardo, La Legitimidad De La Pena Estatal Un Breve Recorrido Por Las Teorías de las Penas, Iustel, Madrid, 2014, p. 45.

13 Es importante anotar que, el delito no responde sólo a causas de exclusión social económica, pues también se manifiesta en sujetos de sectores económicos altos de la sociedad. Así, para el Neorrealismo corriente de la criminología critica la pobreza no es el único factor en la comisión del delito, ya que hay que agregarle otros valores existentes en la sociedad como el individualismo, la competitividad, el deseo de bienes materiales y el machismo formulando la siguiente ecuación: "La carencia relativa produce inconformidad; inconformidad más falta de solución
A manera de ejemplo, uno de los tipos penales que se mencionó en la discusión previa a la entrada en vigencia del NCP, exigiendo que se debía regular con mayores penas es el femicidio (artículo118-A del derogado Código Penal), figura que fue incorporada por adición a dicho texto punitivo según Decreto 23-1013 de fecha 25 de febrero de 2013, vigente a partir del 26 de abril de 2013, con una pena de 30 a 40 años de reclusión, siendo la pena legislada en su momento mayor que la del delito de homicidio y de asesinato cuando no concurre acompañado de robo o violación; evidentemente, la simple comparación con estos delitos que también tutelan el mismo bien jurídico muestra que la pena resultaba desproporcionada, así como la política legislativa que se ofrecía a la ciudadanía en ese momento.

En el NCP (artículo 208) el femicidio se regula en principio con una pena de 20 a 25 años y con la concurrencia de ciertas circunstancias que señala el referido artículo se agrava a 30 años, sin perjuicio de otras penas que se puedan aplicar cuando concurra un concurso de delitos con otros tipos penales que sancionan conductas de violencia contra la mujer, así que la pena no parece ser nada benévola; al revisar las estadísticas de femicidios desde el año que se incorporó la figura, podemos darnos cuenta de lo siguiente: desde el año 2013 a 2018 según datos del Observatorio de la Violencia de la $\mathrm{UNAH}^{14}$, se registran 2879; de los cuales 388 serían del año 2017, ese año se presentaron 22 requerimientos y se obtuvieron 12 sentencias: 6 obtenidas en política producen delito”. Vid. MARTÍNEZ, Mauricio, Qué pasa en la Criminología Moderna, Temis, Bogotá Colombia, 1990, p. 17 .

14 Boletín edición No 14 enero- diciembre de 2018. 
procedimiento abreviado en el cual el acusado se declara culpable para obtener una reducción de la pena ${ }^{15}, 5$ condenatorias y 1 absolutoria en los tribunales de sentencia ${ }^{16}$; en el año 2018 corresponderían 383 casos, ese año también se presentaron 22 requerimientos y se dieron 5 sentencias: 4 condenatorias y una absolutoria en los tribunales de sentencia ${ }^{17}$. Dejando en evidencia el alto margen de impunidad, situación que es similar en la mayoría de los delitos que se cometen.

En consecuencia, se puede concluir objetivamente que el solo hecho de tener penas elevadas no resuelve en nada los problemas delictivos; efectivamente, el femicidio es una de las acciones más ignominiosas contra la mujer basadas en razón del género, inaceptable en una sociedad democrática, pero no es suficiente con la sola tipificación penal, pues se requiere de políticas sociales para combatir la realidad social estructural que genera ese tipo de conductas y, además mucha especialización en la investigación de ese tipo de hechos para poder acreditar la concurrencia de los elementos del delito; antes de la entrada en vigencia del NCP ya una diputada había propuesto reformar el tipo penal de femicidio con un pena de 30 a 40 años, como se regulaba en el Código derogado, con el argumento de ser necesario para frenar la violencia contra las mujeres en el país ${ }^{18}$.

Resulta oportuno recordar a Becaria quien en 1764 sostenía en su famosa obra de los

15 Artículo 403 del Código Procesal Penal

16 Fuente boletín estadístico 2017, Unidad Estadísticas, CEDIJ Poder Judicial.

17 Fuente boletín estadístico 2018, Unidad Estadísticas, CEDIJ Poder Judicial.

18 La Tribuna 13 de mayo de 2020. delitos y de las penas la idea de la efectividad y utilidad de las penas no vista en la crueldad $\mathrm{y}$ atrocidad que pueden producir, sino en su carácter de infalibilidad y de prevención que puedan tener ${ }^{19}$. La mejor apuesta que se puede hacer en una sociedad democrática es la prevención y la efectiva sanción.

En síntesis, el problema del derecho penal no son las penas, es la selectividad de su aplicación, que en muchas oportunidades resulta predeterminada por el poder político al momento de legislar reformas que dificultan el manejo de los casos más complejos, resultando en la praxis más fácil lograr alcanzar a los destinatarios de las prohibiciones penales en delitos comunes como hurtos, robos, homicidios, lesiones y en todos aquellos que son cometidos por los sectores más desprotegidos socialmente, siendo la dinámica de persecución bastante simple la policía de investigación concentra más fácilmente su investigación en estos casos al presentarlos como resueltos el Ministerio Público los consigna automáticamente en la acusación y los tribunales los terminan refrendando como hechos probados en la sentencia penal.

\section{DEL PRINCIPIO DE NECESIDAD DE LA PENA; Y EL PRINCIPIO DE PROPORCIONALIDAD}

19 Sobre la actualidad de Becaria ha escrito el distinguido colega Rafael López Murcia describiendo como en nuestro país usualmente la agravación de penas no ha sido una constante que signifique disminución directa y proporcional en la estadística criminológica, es decir, sin que la mera normatividad incidiera en una disuasión o prevención general del delito. Vid, LOPEZ MURCIA, Rafael, Sobre la Eficacia (Otra Lectura de los Delitos y de las Penas), en Revista Derecho y Razón Núm. 11, Semestre I de 2008, Facultad de Derecho y Ciencias Sociales, UPTC ISSN 16926-3936. 
Como se sabe los derechos garantizados al ciudadano en el ámbito penal se formulan en una serie de principios que limitan el ius puniendi y orientan la aplicación del derecho penal, dichos principios se formulan en forma de límites de carácter normativo, entre los que se distingue entre limites normativos formales y limites normativos materiales o garantías materiales ${ }^{20}$ que son aquellos principios que emanan de la esencia misma del Estado social y democrático de derecho.

Los limites normativos materiales, dentro de los cuales se encuentra el principio de necesidad de la pena y el principio de proporcionalidad, rigen tanto en el proceso de creación de la norma como en la aplicación de la norma, obligando tanto al legislador como al juez, ambos deben observar en sus respectivos ámbitos estos principios y sus consecuencias.

La necesidad de la pena, este principio propio del derecho penal moderno implica establecer un límite al poder punitivo del Estado. La pena debe imponerse solo cuando es necesaria; en caso contrario es un ejercicio arbitrario del poder estatal, de este principio han surgido una serie de postulados que son expresiones más puntuales del mismo, como lo es el caso del denominado principio de extrema ratio, de subsidiariedad y fragmentariedad del derecho penal ${ }^{21}$.

\section{El principio de proporcionalidad de la} pena establece que, no solo es necesario que pueda culparse al autor de lo que conmina la norma penal, sino que además la pena debe 20 Vid. BUSTOS RAMIREZ, Juan, y HORMAZABAL Hernán, op. cit., p.27.

21 Ibíd., p. 34 ser proporcional a la gravedad del hecho cometido, la pena debe tener un límite en razón de la importancia del bien jurídico y la intensidad de su afectación; debiendo reconocerse en la ponderación de la pena a imponer a una persona su dignidad humana, que desde su autonomía ética constituye un ente autónomo, en ese sentido el Estado no puede convertirlo en un mero objeto del control social.

La jurisprudencia de la Sala de lo Penal de la Corte Suprema de Justicia ${ }^{22}$, se ha pronunciado sobre el principio de proporcionalidad, que anteriormente se regulaba en el artículo 2-D, del derogado Código $\mathrm{Penal}^{23}$, diciendo:

Este precepto penal incorpora dos principios del derecho penal, uno el denominado "principio de necesidad" y el otro, el llamado "principio de proporcionalidad". El primero legitima al Estado para intervenir con su poder punitivo por la necesidad de proteger intereses fundamentales de distinto carácter orientados hacia el individuo y que posibiliten a éste la participación en un determinado sistema social, por ello desde los tiempos de la ilustración se ha pregonado que "nullum crimen sine injuria", en consecuencia los debates científicos han formulado el postulado de que el Derecho Penal solo debe proteger bienes jurídicos $\mathrm{y}$, por lo tanto, solo criminalizar conductas socialmente dañosas que atenten contra dichos bienes jurídicos, así, desde un punto de vista valorativo se estima que para que un interés pueda ser objeto de protección penal debe tener un fundamento en el orden constitucional de valores. En cuando al segundo principio (proporcionalidad) en sentido estricto opera fundamentalmente

22 Sentencia de casación S.P. Np 375-09, de fecha 27 de enero de 2011.

23 El mismo principio de proporcionalidad de la pena aparece en el NCP en el artículo 5 al decir: "Principio de Proporcionalidad. La pena se debe fijar atendiendo a la gravedad del hecho y a la culpabilidad del sujeto”. 
en la puesta en relación de esas conductas con las consecuencias jurídicas de las mismas, las penas y las medidas de seguridad, por lo que puede hablarse en este ámbito de "un principio de proporcionalidad de las penas", que a su vez se proyecta, primero, en la fijación legislativa de las mismas, en la conminación legal abstracta, y dentro de ella y de cada delito en su determinación concreta por el juez al aplicar la ley.

En lo referente al principio de proporcionalidad, en la previsión legislativa del delito, en la misma sentencia citada, se señala que:

El principio de proporcionalidad requiere una relación de adecuación entre gravedad de la pena y relevancia del bien jurídico que protege la figura delictiva y a su vez entre la misma y las distintas formas de ataque al bien jurídico que la conducta delictiva puede presentar, es decir, penas más graves reservadas para delitos que atacan los bienes jurídicos más fundamentales, por lo que la medidas máximas de las penas bien puede establecerse a partir de los delitos contra la vida y la salud, pues estos bienes se sitúan en la cúspide del ordenamiento jerárquico de los bienes jurídicos en un Estado de Derecho.

La jurisprudencia de la Sala de lo Penal, también ha reconocido el principio de proporcionalidad de las penas; en uno de los casos que con el anterior Código Penal representaba una problemática en la praxis judicial, referido a la calificación de los hechos consistentes en portar armas de fabricación casera o artesanal comúnmente conocidas como "chimbas", existiendo diferentes criterios jurídicos para calificar esas conductas; algunos tribunales consideraban que debía ser sancionada de conformidad al artículo 332-A ( Código derogado), que regulaba el tipo de Fabricación y Trafico de
Material de Guerra, Armas y Municiones con una pena de ocho ( 8) a diez (10) años y multa de cinco mil (L5,000.00) a diez mil (L10,000.00) por cada arma incautada; otros tribunales consideraban que, de acuerdo al calibre las armas caseras debía enmarcarse en el artículo 332-B ( Código derogado), que regulaba el tipo de Fabricación y Tráfico de Armas de Fuego y Municiones Comerciales, de Defensa Personal o Deportivas y Explosivos Comerciales, sancionado con pena de tres (3) a seis (6) años; y, otra posición que no podía calificarse el hecho con ninguna de las dos normas referidas.

$\mathrm{Al}$ respecto, la Sala de lo Penal $^{24}$ estableció, que dicha conducta no se podía considerar comprendida dentro del artículo 332-A, referido; pero partiendo de las características objetivas de las armas caseras y su potencial grado de peligrosidad la fabricación o la portación de las "chimbas" se podía considerar como de uso personal y haciendo una adecuación proporcional de la pena regulada en estos tipos penales la conducta debía ser calificada con el artículo 332-B, del derogado Código Penal que establecía una pena menor en relación al 332-A del mismo Código.

Ahora en el NCP, en su artículo 580 se sanciona la tenencia de armas sin permiso, de la siguiente manera: 1) De uno (1) a cuatro (4) la tenencia de armas o municiones permitidas; $y, 2$ ) De cuatro (4) a seis (6) años si se trata de armas o municiones prohibidas; además se sanciona expresamente las armas artesanales con la misma pena prevista para las armas permitidas (criterio que ya había asumido la Sala de lo Penal).

24 Sentencia de casación S.P. No 467-2012, de fecha 22 de septiembre de 2014 . 
Haciendo también el NCP una separación en cuanto a la "portación" y agravándola en un tercio $(1 / 3)$ en cualquiera de los casos antes señalados, estableciendo así una adecuación más proporcional de la pena al distinguir los conceptos de tenencia y portación que en el anterior Código aparecían en el mismo supuesto al igual que el almacenamiento depósito y fabricación, que ahora se regulan en los artículos 581 y 582 respectivamente con una pena más elevada por representar conductas de mayor peligrosidad.

\section{EL FIN DE LAS PENAS EN UNA SOCIEDAD DEMOCRÁTICA}

El monopolio estatal del ius puniendi obliga ineludiblemente al Estado a legitimar la función punitiva desde una perspectiva de límites racionales en razón de la utilidad social que se le asigne a la pena, salvo que se pretenda fundamentar la pena en el puro sentimiento de venganza ${ }^{25}$, lo cual desnaturalizaría la existencia de los ideales democráticos del Estado; en la legitimación de la pena solo puede incluirse la forma en que la pena trascenderá en aseguramiento de la libertad jurídica y en el desarrollo del propio sistema jurídico.

Desde la perspectiva de la utilidad social la legitimación de la pena debe radicar en su

25 El mismo Hegel postulaba una dimensión social e intersubjetiva de la que carecían las formulaciones kantianas, la pena debía tener para la sociedad que castiga un valor simbólico equivalente al delito, lo decisivo no es el aspecto externo del delito y la pena, mal que sigue a otro mal, sino su sentido simbólico o comunicativo para el derecho. La ley del talión solo conduce a que haya dos tuertos o dos destentados sin que ello por sí mismo tenga sentido. Vid. FEIJOO, Bernardo, La Legitimidad de la Pena Estatal un Breve Recorrido Por Las Teorías de las Penas, Iustel, Madrid, 2014, p.59. naturaleza social, es decir, en la necesidad de la sociedad de que se imponga una pena en el caso concreto, no se debe incurrir en el error de buscar la justificación únicamente en el análisis entre el sujeto que comete el hecho ilícito que es sancionado y el Estado que la impone; ello sería como pretender ver las normas que garantizan la libertad de conducta, únicamente como un vínculo exclusivo entre el destinatario de la norma y el Estado, sin considerarlo como un vínculo que enlaza a todos los ciudadanos entre sí con el Estado; por ello, la pena exige que exista una necesidad social más allá de la mera vulneración de la norma de conducta. Así como el merecimiento de pena representa un juicio general de desvalor, la necesidad de pena representa un juicio general de conveniencia.

Razón por la cual, por ejemplo, se acepta que con el paso del tiempo se atenúe o se haga desaparecer la necesidad social de la pena por prescripción ${ }^{26}$, o que se permita excluirla en ciertos casos que por consideraciones de política criminal se ha regulado el principio de oportunidad, de igual forma la decisión que algunos delitos culposos queden sin pena siguiendo el sistema de números clausus (sistema cerrado de crimina culposa) a texto expreso como lo hacía el derogado Código en su artículo $13 \mathrm{y}$, se sigue manteniendo en el NCP en el párrafo segundo del artículo 18 del delito imprudente, siendo evidente que la decisión de penalizar un comportamiento es una decisión de ejercicio de poder, de política criminal en el caso de la creación de los delitos.

26 Cfr. MEINI, Iván, La Pena Función y Presupuesto, en Derecho PUCU No 71, 2013, ISSN O2 51-3420, p. 143. 
Ciertamente, el tema de la justificación de las penas no es ni ha sido pacifico en el Derecho penal, así desde las distintas teorías que pretenden justificarla se viene debatiendo cual debe ser la limitación del poder punitivo del Estado, pues en una democracia el poder punitivo debe estar adecuado a la retribución jurídica de un delito predeterminado, proporcionado a su gravedad y debido al reproche de culpabilidad que se le pueda atribuir subjetivamente al infractor.

En síntesis, las posiciones fundamentales sobre el sentido y los límites de las penas se plantean en:

a) Las teorías absolutas, la pena retribuye o expía la culpabilidad del autor; se les denomina teorías retributivas, precisamente porque no buscan la prevención del delito, la pena no recibe una función social, quedándose únicamente en la mera retribución por un mal (delito) causado, así entendidas no son teorías de las penas, sino teorías penales ${ }^{27}$.

El famoso ejemplo de Kant de la isla ilustra el concepto de las teorías absolutas diciendo: "Aun cuando se disolviera la sociedad con el consentimiento de todos sus miembros, antes tendría que ser ejecutado hasta el último asesino que se encuentre en la cárcel para que cada cual reciba lo que merecen sus actos". No extraña entonces que las ideas filosóficas que subyacen en las teorías absolutas conciban al hombre como sujeto capaz de autodeterminarse así mismo y al Estado como el guardián de la justicia terrestre y de la moral, habiendo sido estas teorías defendidas no solo

27 Ibíd., p. 145.

12. Revista de Derecho. Vol. 41, No. 1, Año 2020 con argumentos jurídicos, sino también desde postulados religiosos y éticos ${ }^{28}$ concepto de expiación y retribución que no se puede sostener actualmente desde la perspectiva jurídica.

b) Las teorías de la prevención general, ideada por FEUERBACH pretende prevenir futuros delitos dirigiéndose al público en general; la idea de prevención general busca limitar el poder punitivo estatal, debido a que la conminación legal impuesta en la norma penal actuara como una advertencia general que sirva para prevenir ex ante la comisión de delitos, al prevenir a otras personas que no hagan lo hecho por la persona castigada con una pena. Estas teorías se manifiestan por medio de la prevención general negativa, que pretende la prevención del delito por medio de la amenaza e intimidación de llegar a sufrir una pena; pero también se manifiesta a través de la prevención general positiva, que busca educar a la colectividad acerca de los valores protegidos con las sanciones, reconocimiento positivo del orden jurídico.

En la actualidad como se sabe, la idea de que los delincuentes sopesan racionalmente los costos del crimen en la forma de penas, contra sus beneficios, ha sido criminológicamente desacreditada como formula general, pues resulta obvio que no se aplica a crímenes pasionales o aquellos cometidos bajo la influencia del alcohol ${ }^{29}$, la mayoría de los delincuentes no realizan un cálculo racional

28 Cfr. MIR PUIG, Santiago, Derecho penal, Parte General, $6^{\circ}$ edición, Barcelona, Reppertor, 2002, p. 83 y ss.

29 ROTMAN, Edgardo, La Prevención Del Delito, Investigaciones Jurídicas, S.A. Costa Rica, 1988, p. 85. 
de posibles costos y beneficios antes de delinquir y ni siquiera conocen las penas que corresponden a los hechos delictivos ${ }^{30}$.

c) La prevención especial, desarrollada por VON LISZT, no quiere retribuir el hecho pasado, sino prevenir nuevos delitos del autor, es la que se manifiesta al momento de la ejecución de la pena, la utilidad se pretende en la resocialización o rehabilitación del condenado ${ }^{31}$, a través no solo del cumplimiento de la pena, sino también en una intervención de la conducta humana con medidas psicoterapeutas, educacionales buscando reeducar al privado de libertad y que pueda ser al cumplimiento de la pena reinsertado dentro de la sociedad sin peligro de nocividad para la colectividad, fin de utilidad social; conocido es que las cárceles en nuestro medio no representan ni han representado posibilidad alguna de rehabilitación el uso excesivo de la pena de privación de libertad ha servido únicamente para trasladar la violencia de las calles a los centros penales, que en muchas ocasiones terminan siendo gobernados "paralelamente" por los mismos reclusos.

Ciertamente, el problema que presenta la resocialización como idea legitimadora de la pena. Es cómo el infractor podrá resocializarse si se le confina a un centro penitenciario en donde el contacto social es restringido cuando no nulo- y donde imperan códigos

30 Vid. FEIJOO, Bernardo, op. cit., p. 46.

31 La prevención especial significa que con la pena se buscan determinados efectos en la persona condenada para que no vuelva delinquir en el futuro, es decir el fin de la pena seria prevenir la reincidencia. Ibíd., p. 59. de conducta (o de supervivencia) que distan mucho del modelo que la resocialización pregona como válido para la convivencia pacífica y que rigen fuera de prisión.

Si bien es verdad que el trabajo y la educación permiten redimir parte de la pena y que esto podría ser visto como una preparación para la vida en sociedad, también lo es que las carencias materiales de los estados impiden que en la mayoría de los casos el trabajo o estudio al interior del centro penitenciario cumpla dicho objetivo ${ }^{32}$.

La prevención especial no puede por si sola, justificar el recurso a la pena: en algunos casos la pena no será necesaria para la prevención especial, en otros no será posible y, finalmente, en ocasiones no será licita, y, sin embargo, seria absurda la impunidad del sujeto $^{33}$.

d) Teoría ecléctica, ante las críticas expuestas a las teorías anteriores, la propuesta ecléctica hace una mixtura de todas, entendiendo que, la retribución, la prevención general y la especial son distintos aspectos que componen la pena; para ROXIN el punto de partida de toda teoría hoy defendible debe basarse en el entendimiento de que el fin de la pena sólo puede ser de tipo preventivo. Puesto que las normas penales sólo están justificadas cuando tienden a la protección de la libertad individual y a un orden social que está a su servicio ${ }^{34}$.

32 Cfr. MEINI, Iván, op. cit., p. 149.

33 MIR PUIG, Santiago, op. cit., p. 92.

$34 \mathrm{El}$ autor citado agrega también que la pena concreta sólo puede perseguir un fin preventivo del delito. Vid. ROXIN, Claus, op. cit., p. 95. 
El punto de partida de la unión es reconocer que ni la culpabilidad del sujeto ni la prevención por sí solas son capaces de legitimar la sanción penal, y rechazar que la retribución de la culpabilidad tenga cabida en la legitimación de la pena al no poder explicarse metafísicamente una intervención estatal como la pena. Según esta concepción, la pena cumple funciones de prevención especial y de prevención general, y queda limitada por la culpabilidad del sujeto, lo que la haría proporcional frente a su responsabilidad ${ }^{35}$.

En nuestra constitución ${ }^{36}$ aparecen 2 normas que hacen una clara referencia al tema de las penas y al ámbito de su ejecución; la primera en el artículo 87, dispone:

Las cárceles son establecimientos de seguridad y defensa social. Se procurará en ellas la rehabilitación del recluido y su preparación para el trabajo.

Ciertamente, el constituyente se decantó por una posición mixta señalando primero que las cárceles son centros de "defensa y seguridad social", término que alude al positivismo criminológico ${ }^{37}$, según el cual la cárcel debía servir para aislar a los infractores y mantener segura a la colectividad; pero a la vez la norma constitucional hace el llamado

35 Cfr. MEINI, Iván, op. cit., p. 155.

36 De igual forma también el principio de legalidad (artículo $95 \mathrm{CR}$ ) expresado en el axioma: nullum crimen, nulla poena, sine lege, comprende dicho principio la garantía criminal, la garantía penal, la garantía jurisdiccional; así como la garantía de ejecución referida a la ejecución de la pena en estricto apego a una ley que regule derechos de los privados de libertad 37 Enrico Ferry y Lombroso sostenían la defensa social considerando que la pena era el mecanismo para defender a la sociedad de la peligrosidad de ciertos individuos, el delito se consideraba el síntoma de la personalidad peligrosa y la pena algo así como el remedio que se aplica a dicha persona para corregirla. a la rehabilitación para el trabajo (prevención especial); en la Ley del Sistema Penitenciario Nacional (Decreto 64-2012) se reconoce la protección de la sociedad y la rehabilitación como fines primordiales del sistema penitenciario; visto a la luz del derecho convencional y la obligatoriedad que impone al Estado el artículo 5. 6. de la Convención Americana Sobre Derechos Humanos, dicha disposición es precisa y reconoce como único fin de las penas la reforma y la readaptación social de los condenados, imponiendo implícitamente los principios de necesidad y proporcionalidad de la pena.

La resocialización se convierte en el medio con el cual los estados deben de proveer la seguridad jurídica de los ciudadanos. La rehabilitación es el único fin de la pena que obliga al Estado a ocuparse de las necesidades y bienestar de los presos; La ideología de la rehabilitación supone una racional respuesta a la idea conservadora de que el incremento punitivo reduce el delito.

La segunda, en el artículo 68, que en su párrafo segundo y tercero respectivamente dice:

Nadie debe ser sometido a torturas, ni penas o tratos crueles, inhumanos o degradantes.

Toda persona privada de libertad será tratada con el respeto debido a la dignidad humana.

Una particularidad de los textos constitucionales es la frecuente abundancia de expresiones que contienen lo que en la literatura filosófica se denomina conceptos "esencialmente controvertidos" 38 ,

38 Vid. FERRERES COMELA, Víctor, Justicia Constitucional y Democracia, Centro de Estudios Políticos y Constitucionales, 
entendiéndose por aquellos que expresan un criterio normativo que puede presentar desacuerdo de interpretaciones en cuanto al contenido específico del criterio contenido; cuando la constitución prohíbe las penas o tratos crueles, inhumanos o degradantes utiliza expresiones controvertidas, un trato o castigo cruel, inhumano o degradante conlleva una condición más grave de lo aceptable para quien lo sufre, pero la discrepancia controvertida que puede presentar la norma solo acepta juicios de valor en lo referente a lo grave de la pena en su ejecución desde el punto de vista de quien la sufre, sin llegar a otros aspectos valorativos, tales como si la pena impuesta es suficiente para satisfacer los derechos de las víctimas.

Las penas que no guardan el principio de proporcionalidad serán crueles, inhumanas y degradantes ${ }^{39}$, pues de entrada vedan la posibilidad de resocialización alguna como derecho del privado de libertad ${ }^{40}$.

\section{LAS PENAS EN EL NUEVO CÓDIGO PENAL}

Madrid, 2007, p. 27.

39 El artículo 2 de la Convención Interamericana Para Prevenir y Sancionar la Tortura, establece: "Para los efectos de la presente Convención se entenderá por tortura todo acto realizado intencionalmente por el cual se inflijan a una persona penas o sufrimientos físicos o mentales, con fines de investigación criminal, como medio intimidatorio, como castigo personal, como medida preventiva, como pena o con cualquier otro fin. Se entenderá también como tortura la aplicación sobre una persona de métodos tendientes a anular la personalidad de la víctima o a disminuir su capacidad física o mental, aunque no causen dolor físico o angustia psíquica”. (La negrita es agregada).

40 La Corte IDH., ha manifestado que toda persona privada de libertad tiene derecho a vivir en situación de detención compatible con su dignidad humana. Caso. Tibi Vs Ecuador, sentencia de 07 de septiembre de 2004, párrafo. 150.; Cantoral Benavides Vs Perú, Sentencia de 18 de agosto de 2000.
El NCP, contrario al Código derogado ${ }^{41}$, incorpora una clasificación más amplia de las distintas penas que pueden imponerse; evidenciando a pima facie una clara decisión de política criminal de disminución del uso de la pena de prisión en todos los supuestos delictivos. Así en su artículo 34, se establecen penas privativas de la libertad, penas privativas de otros derechos y multas, ya sean con carácter principal o accesorias.

Clasificándolas por su naturaleza y duración. De conformidad con el artículo 35 por su naturaleza se consideran:

\section{Penas privativas de libertad:}
a) La prisión a perpetuidad;
b) La prisión;
c) El arresto domiciliario; $y$,
d) La detención de fin de semana.

\section{Penas privativas de otros derechos:}

a) La expulsión del territorio nacional;

b) La prestación de servicios de utilidad pública o a las víctimas;

c) La privación del derecho de conducción de vehículos automotores, aeronaves y embarcaciones;

d) La privación de los derechos a la tenencia y portación de armas de fuego, explosivos y similares;

e) La inhabilitación para obtener subvenciones y ayudas públicas, para contratar con el sector público y para gozar de los beneficios o incentivos fiscales o de la Seguridad Social;

41 Para el análisis comparativo de las penas que se regulaban en el Código Penal derogado, se establecía en su artículo 38 como penas principales: La reclusión, la prisión, la multa, la inhabilitación absoluta y la inhabilitación especial; y, como penas accesorias: La interdicción civil y el comiso. 
f) La suspensión de la ciudadanía;

g) La pérdida de nacionalidad;

h) La inhabilitación absoluta;

i) La inhabilitación especial de cargo u oficio público;

j) La inhabilitación especial de profesión u oficio, industria o comercio;

k) La inhabilitación especial de la patria potestad, tutela, guarda o curatela;

1) La prohibición de residencia;

m) La prohibición de aproximarse o comunicarse con la víctima; y,

n) La localización permanente.

\section{Penas de multa:}

a) Los días-multa; $y$,

b) La multa proporcional.

El artículo 36 establece que en función de su duración se clasifican en graves y menos graves:

\section{Penas graves:}

a) La prisión a perpetuidad;

b) La prisión superior a cinco (5) años;

c) Las privaciones de los derechos a conducir vehículos automotores, aeronaves y embarcaciones, a la tenencia y portación de armas de fuego, explosivos y similares, superiores a cinco (5) años;

d) La pérdida de la nacionalidad;

e) Suspensión de la ciudadanía;

f) La inhabilitación absoluta;

g) Las inhabilitaciones especiales superiores a cinco (5) años; y,

h) Las prohibiciones de residencia o de aproximarse o comunicarse con la víctima superiores a cinco (5) años.

\section{Penas menos graves:}

a) La prisión de seis (6) meses a cinco (5) años;

b) Arresto domiciliario de seis (6) meses a tres (3) años;

c) La detención de fin de semana superior a quince (15) fines de semana;

d) La prestación de servicios de utilidad pública o a las víctimas igual o superior a noventa (90) días;

e) Las privaciones de los derechos a conducir vehículos automotores, aeronaves y embarcaciones, a la tenencia y portación de armas de fuego, explosivos y similares, superiores a un (1) año hasta cinco (5) años;

f) Las prohibiciones de residencia o de aproximarse o comunicarse con la víctima superiores a seis (6) meses hasta cinco (5) años;

g) Las inhabilitaciones especiales superiores a un (1) año hasta cinco (5) años;

h) La localización permanente superior a seis (6) meses hasta cinco (5) años;

i) Los días-multa igual o superior a cien (100) días; y,

j) La multa proporcional.

\section{Penas leves:}

a) La prisión inferior a seis (6) meses;

b) El arresto domiciliario de menos de seis (6) meses;

c) La detención de hasta quince (15) fines de semana;

d) La prestación de servicios de utilidad pública o a las víctimas inferior a noventa (90) días;

e) Las privaciones de los derechos a conducir vehículos automotores, 
aeronaves y embarcaciones, a la tenencia y portación de armas de fuego, explosivos y similares, de tres (3) meses a un (1) año;

f) Las inhabilitaciones especiales de tres (3) meses a un (1) año;

g) Las prohibiciones de residencia o de aproximarse o comunicarse con la víctima de hasta seis (6) meses;

h) La localización permanente hasta seis (6) meses; e,

i) La multa inferior a cien (100) días.En los artículos 37 al 56 se detalla en que consiste cada una de las penas antes señaladas los cuales deben verse para su mejor comprensión.

\section{A MANERA DE CONCLUSIÓN}

Cuando se recurre a penas innecesarias, inútiles o desproporcionadas, se desborda el marco del Estado de derecho y se cae en el terror penal, buscando tratar de ocultar las fallas del sistema con la amenaza de penas altas sin que pueda afirmarse que con el endurecimiento de las penas como sucedía en el Código Penal derogado se hubiese podido disminuir la criminalidad en sus distintas tipologías.

El Derecho penal debe garantizar la protección de los bienes jurídicos de los ciudadanos, previniendo los delitos, debiendo orientar la función preventiva de la pena de acuerdo con los principios de lesividad, necesidad, proporcionalidad y culpabilidad.
La imposición de penas siempre debe estar vinculada al respeto de la dignidad humana, pues ningún poder puede ser ejercido legítimamente desconociendo ese referente material; caso contrario el Derecho penal se convierte en un mero instrumento de persecución penal sin límites, que instrumentaliza al ser humano.

Claramente, en el NCP aparece una regulación más amplia de las penas que se pueden imponer, evidenciándose, que en la nueva normativa además de la pena privativa de libertad se opta por la posibilidad de utilizar penas de distinta naturaleza y gravedad; sobre ello, debe anotarse, que la diversidad de contar con un amplio arsenal punitivo puede permitir reacciones más idóneas y proporcionales a la naturaleza y gravedad de la infracción, así como a las necesidades sociales existentes al momento de la condena en el caso concreto.

Al respecto, como bien ha señalado la doctrina $^{42}$ debe tenerse en cuenta, que en la legitimación de la pena no puede limitarse a una modalidad de pena en concreto. Debe tenerse presente la totalidad del arsenal punitivo. Este aspecto suele pasar desapercibido, como lo demuestra el hecho de que la discusión sobre la pena, una vez superada la pena de muerte, gire en torno a los fines de la pena privativa de libertad, y solo en ocasiones excepcionales se incluyan otras penas, como la restrictiva de libertad, limitativa de derechos y multa. Un análisis que no tenga en cuenta este detalle no podrá justificar la pena como institución jurídica. Lejos de ello, correrá el riesgo

42 Cfr. MEINI, Iván, op. cit., p. 143. 
de encasillar todos los comportamientos merecedores de pena como comportamientos merecedores de pena privativa de libertad.

\section{BIBLIOGRAFÍA}

BACIGALUPO, Enrique, Manual de Derecho Penal, Temis, Bogotá, 1996.

BALAGUER CALLEJON, María Luisa, Interpretación de la Constitución y Ordenamiento Jurídico, Tecnos, Madrid, 1997.

CRUZ CASTRO, Fernando, La Pena Privativa de Libertad: Poder Represión y Constitución, Editorial Jurídica Continental, Costa Rica, 2004.

FERRERES COMELA, Víctor, Justicia Constitucional y Democracia, Centro de Estudios Políticos y Constitucionales, Madrid, 2007.

FEIJOO, Bernardo, La Legitimidad De La Pena Estatal Un Breve Recorrido Por Las Teorías de las Penas, Iustel, Madrid, 2014.

LÓPEZ MURCIA, Rafael, Sobre la Eficacia (Otra Lectura de los Delitos y de las Penas), en Revista Derecho y Razón Núm. 11, Semestre I de 2008, Facultad de Derecho y Ciencias Sociales, UPTC ISSN 169263936.

LLOBET RODRIGUEZ, JAVIER, Populismo Penal, en Revista Digital de la Maestría de Ciencias Penales No 8 Año 8.
MIR PUIG, Santiago, Derecho Penal, Parte General, $6^{\circ}$ edición, Barcelona, Reppertor, 2002.

MEINI, Iván, La Pena Función y Presupuesto, en Derecho PUCU No 71, 2013, ISSN 02 51-3420.

MARTÍNEZ, Mauricio, Qué pasa en la Criminología Moderna, Temis, Bogotá Colombia, 1990.

ROTMAN, Edgardo, La Prevención Del Delito, Investigaciones Jurídicas, S.A. Costa Rica, 1988.

PARRA GONZALEZ, Ana Victoria, "Medios Opinión Publica y Corrupción", en CAPPAROS, Eduardo y PEREZ CEPEDA, Ana, Estudios Sobre Corrupción, Ratio Legis, Salamanca, 2010.

ROXIN, Claus, Derecho Penal, Parte General, Civitas, Madrid, 1997.

SOTOMAYOR ACOSTA, Juan y TAMAYO ARBOLEDA, Fernando, La Nueva Cuestión Penal y Los Retos de Una Ciencia Penal Garantista, en Revista Nuevo Foro Penal, Vol. 10 No. 82 enero -junio 2014.

SUAZO LAGOS, Rene, "La Evolución del Derecho Penal en Honduras", en CALIX HERNÁNDEZ, Jacobo, Temas de Derecho Penal, Libro Homenaje a José María Palacios, Corte Suprema de Justicia, Litografía López, 2014. 